\title{
REPORT OF A FEMININE CASE
}

UNIEESSIDAEF D COIMBRA U

\section{INTRODUCTION}

Sexual dependence presents a pattern of sexual maladaptive behavior associated with persistent, recurrent and intense sexual intensities. As generational manifestations, they interfere negatively on the personal, occupational and / or social level with emotional generation, interpersonal, legal and health problems.

The patient's history can often expand in sexual activities sometimes or for longer than initially intended; unsuccessful attempts to reduce or control sexual behavior; excessive spending of rhythm in activities related to this sexual behavior; withdrawal of social, occupational or recreational activities as a result of such sexual behavior; continued sexual activity despite the fact that it presents hot social, financial, psychological or

\section{OBJECTIVES}

To present a case report of hypersexuality that makes a brief review of the literature and shows criteria of good reliability to make the diagnosis. of the same levels of pleasure; restlessness

\section{MATERIAL AND METHODS}

Description of the clinical case of a patient hospitalized at the Hospital of the University of Coimbra using Goodman's diagnostic criteria (table 1) and the Sex Dependency Screening Scale (SDSS). The SDSS contais 25 questions and aims to identify cases of gender dependency. One point is attributed to each of the positive responses to scale issues. Negative replies do not get scores.

\section{Table 1 - Diagnostic criteria for sex dependence Pattern of maladaptive behavior, causing discomfort or signifi- cant clinical manifestation, manifested by three (or more) of the following characteristics, persistent for a period of 12 months:}

1. Frequent involvement in sexual activities more often or longer than initially intended

2. Unsuccessful attempts to reduce or control sexual behavior

3. Excessive time spent in activities related to this sexual behavior

4. Withdrawal of social, occupational or recreational activities as a result of such sexual behavior

5. Continuity of sexual activity despite frequently presenting social, financial, psychological or physical problems caused by this behavior

6. Progressive need to increase the frequency or intensity of sexual activity to achieve the same levels of pleasure

7. Restlessness or irritation at the inability to engage in sexual activity

\section{CASE REPORT}

A 34-year-old female patient with a history of Major Depressive Disorder, admitted to the Psychiatric Service with high levels of anxiety, depressive mood and suicidal ideation, presented a pattern of disappointing behavior, scoring 13 of 25 points on SDSS. It was found that depressive symptoms were secondary to compulsive sexual behavior from early adolescence. Treatment with paroxetine was initiated and, after 28 days of hospitalization, she claimed absence of sexual thoughts and unchanged sleep, continuing until the 33rd day, when she was discharged from the service, and only the outpatient follow-up of the case was recommended.

\section{DISCUSSION}

Sexuality depends on many factors, including individual variables of relationships, societal values, cultural customs, ethnic and religious beliefs. When discussing hypersexuality, the context needs to be considered. The majority of individuals with hypersexuality are male, with a prevalence of $8 \%$ to $40 \%$ in females. Treatment should be based on a thorough assessment tailored to the specific needs of the patient, and because it is a complex disorder, requires a multifaceted approach, including cognitive-behavioral therapy, relapse prevention therapy, psychodynamic psychotherapy, and psychopharmacological treatment. Paroxetine is the most potent in the selective serotonin reuptake inhibitor (SSRI) class with antidepressant and anxiolytic properties and appears to have slightly higher rates of libido loss compared to other SSRIs.

\section{CONCLUSION}

Sexual dependence is capable of generating damages in the biological, psychological and social sphere during the life of the patients. However, the drug treatment, psychotherapeutic and guidance of health professionals are able to reduce or avoid the disorders generated.

\section{REFERENCES}

1. M M Campbell, D J Stein. Hypersexual disorder in general practice. SAMJ June 2014, Vol. 104, No. 6 2. Meg S. Kaplan and Richard B. Krueger. Diagnosis, Assessment, and Treatment of Hypersexuality JOURNAL OF SEX RESEARCH, 47 (2-3), 181-198, 2010

3. Dartiu X Silveira, Aderbal C Vieira, Victor Palomo e Evelyn D Silveira. Validade de critério e confiabilidade da versão brasileira de uma escala de rastreamento para dependência de sexo. Rev Bras Psiquiat 2000;22(1):4-1

4. Maria Luiza Sant'Ana do Amaral; Marco de Tubino Scanavino. Comportamentos Sexuais Compulsivos graves: relato de dois casos em tratamento. Rev Bras Psiquiatr. 2012;34:213-216

5. Paroxetine: current status in psychiatry. Journal Expert Review of Neurotherapeutics ; Pages 107-120 | Published online: 09 Jan 2014

6. Goodman A. Addiction: definition and implications. Br J Addict 1990;85:1403-8. 